Journal of Animal \& Plant Sciences, 31(5): 2021, Page: 1302-1308

ISSN (print): 1018-7081; ISSN (online): 2309-8694

https://doi.org/10.36899/JAPS.2021.5.0331

\title{
THERAPEUTIC POTENTIAL OF OZONE AND L-CARNITINE COMBINED ADMINISTRATIONS AGAINST EXPERIMENTALLY-INDUCED ACETAMINOPHEN
}

\author{
E. Paldir ${ }^{1}$ and H. A. Eroglu ${ }^{2 *}$ \\ ${ }^{1}$ Buharkent District State Hospital, Aydın, Turkey \\ ${ }^{2}$ Çanakkale Onsekiz Mart University, Medical School, Department of Basic Medical Sciences, Çanakkale, Turkey, \\ 17100 \\ *Corresponding author's email: haeroglu@comu.edu.tr
}

\begin{abstract}
Acetaminophen is a widely used medicine with antipyretic and analgesic effects. N-acetyl-P-benzoquinoneimine accumulation after a high-dose of acetaminophen leads to hepatotoxicity, depletion of glutathione stores, and suppression of the antioxidant defense mechanism. As a result, $\mathrm{N}$-acetyl-P-benzoquinoneimine cannot be eliminated from the body and hepatotoxicity occurs. In this study, the effects of the separate and combined use of ozone and L-carnitine in high-dose acetaminophen induced hepatotoxicity was investigated. A total of 56 female Wistar albino rats were randomly divided into 8 groups of seven rats. Acetaminophen was administered orally as a single dose to induce liver damage, and $0.5 \mathrm{mg} / \mathrm{kg}$ of $95 \%$ oxygen plus $5 \%$ ozone gas mixture was administered intraperitoneally. After 1-hour APAP administration, Lcarnitine were given $500 \mathrm{mg} / \mathrm{kg}$ by intraperitoneally. Serum and tissue oxidant/antioxidant parameters were measured to deduce their combined effect. ANOVA and Tukey's multiple comparison test were used for statistical analysis. Acetaminophen+L-carnitine+ozone administration caused a significant decrease in the levels of serum malondialdehyde, total oxidant level, aspartate aminotransferase, alanine aminotransferase, and tissue malondialdehyde, total oxidant status levels, while it led to a significant increase in the levels of tissue and serum total antioxidant levels. Nonetheless, a clear evidence of superiority over the sole use of ozone or L-carnitine in acetaminophen induced hepatotoxicity was not present. It was concluded that ozone, L-carnitine and ozone + L-carnitine treatments in acetaminophen induced hepatotoxicity protected the organism against the harmful effects of free radicals and activated the antioxidant mechanism by suppressing oxidative stress.
\end{abstract}

Keywords: Acetaminophen, Hepatotoxicity, L-carnitine, Liver, ozone Published first online January 21, 2021 Published Final 07, 2021.

\section{INTRODUCTION}

Acetaminophen (APAP) is a widely used medicine with antipyretic and analgesic actions. It is one of the most commonly preferred drugs owing to lower cost and over-the-counter availability without a prescription. Therapeutic doses of APAP are considered safe, while its overdose was noted to be lethal in humans and animals (Lee, 2017). APAP toxicity is reported to be responsible for $46 \%$ of all acute liver failure in the United States (US) and up to $70 \%$ of all cases in the United Kingdom and Europe (Ostapowicz et al., 2002; Bernal et al., 2010). The maximum daily adult dose of acetaminophen is $4 \mathrm{gm}$ with a therapeutic dose of 500-1000 mg, which can be given orally in 4-6-hour intervals. A single dose of $150 \mathrm{mg} / \mathrm{kg}$ and more is considered as toxic; however, $300 \mathrm{mg} / \mathrm{kg}$ and more can even be lethal (Ostapowicz et al., 2002; James et al., 2003; Ranganathan et al., 2006; Lee, 2017).

When used at therapeutic doses, APAP is metabolized by the liver and is excreted from the kidneys with glucuronic acid and sulfate conjugates. However, a small amount of APAP is metabolized by cytochrome P450 (CYP450) enzymes to N-acetyl-P-
benzoquinoneimine)NAPQI( , which is subsequently detoxified by glutathione )GSH.( NAPQI accumulation after a high-dose of APAP leads to hepatotoxicity, depletion of GSH stores, and suppression of the antioxidant defense mechanisms. As a result, NAPQI cannot be eliminated from the body and hepatotoxicity occurs due to its accumulation (Abiko et al., 2015).

$\mathrm{N}$-acetyl-cysteine (NAC) administration is the most commonly used treatment for acetaminophen toxicity. Although the protective effects of NAC administration such as replacing reduced GSH resources and limiting hepatotoxicity have been approved by scientific studies, hepatotoxicity can be observed even in the case of NAC administration (Doyon and KleinSchwartz, 2009).

Ozone, a colorless gas with a pungent odor, is formed by the decomposition of the oxygen molecule into the unstable oxygen atoms that combines with another oxygen molecule (Sobczyńska-Rak et al., 2019). The use of gas mixture comprising ozone/oxygen is routinely utilized in medicine for various purposes and the procedure is known as medical ozone therapy (Demirbag et al., 2010). Ozone was demonstrated to increase the antioxidant enzyme activities to overcome 
physiopathologic conditions mediated by reactive oxygen species (ROS) (Bocci et al., 2011; Sobczyńska-Rak et al., 2019). Ozone activates the cell metabolism, strengthens the immune system, increases oxygen content in the tissues by increasing the oxygen carrying capacity of hemoglobin after stimulating erythrocyte metabolism, and decreases the levels of free radicals (Li et al., 2007; Bocci et al., 2011).

L-carnitine a cofactor in the transfer of the long chain fatty acid in the inner mitochondrial membrane and can be synthesized in the body. L-carnitine with its free radical scavenging ability reduces the free radicals and thus has antioxidant activity. It also helps to increase cellular energy production by preventing cellular and mitochondrial damage and protecting the cell membrane against the harms caused by free radicals in the cell. As APAP hepatotoxicity is thought to arise from mitochondrial dysfunction and oxidative stress, Lcarnitine is tested in the APAP hepatotoxicities and its regenerative effect is reported in several animal models (Ghirardi et al., 1989; Bhattacharyya et al., 2013; Demiroren et al., 2014).

It is clear that diminishing oxidative stress caused by APAP hepatotoxicities can be achieved through treatment with various antioxidants (Ghirardi et al., 1989; Demirbag et al., 2010; Bocci et al., 2011; Bhattacharyya et al., 2013; Demiroren et al., 2014; Sobczyńska-Rak et al., 2019). Nevertheless, combining multiple treatment was suggested to be an effective strategy for reducing oxidative stress caused complications and was indicated to be effective in diabetic (Saleh et al., 2014). Although, the therapeutic potential of ozone and L-carnitine in high-dose APAP-induced hepatotoxicity was documented separately in experimental animal systems, no study has tested the relative effectiveness of combining the two therapeutic agents.

Therefore, this study, aimed to investigate the combined effect of ozone and L-carnitine in high-dose APAP-induced hepatotoxicity by measuring antioxidant parameters and biochemical alterations in the blood and liver tissue in rats.

\section{MATERIALS AND METHODS}

Experimental Groups and Procedure: Prior to the study, the ethical approval was obtained from the Animal Experiments Local Ethics Board of the Kafkas University (KAU-HADYEK/2016-042). A total of 56 female Wistar albino rats of 4-6-weeks old and weighing 190 -250 g were obtained and used in this study.

Animals were randomly divided into 8 groups of seven rats (control and 7 experimental groups) as follow: (a) Control Group $(\mathrm{n}=7)$ : Only $0.9 \% \mathrm{NaCl}$ was given orally. (b) $\mathrm{O}_{3}$ Group (n=7): $0.5 \mathrm{mg} / \mathrm{kg}$ of $95 \%$ oxygen plus $5 \%$ ozone gas mixture was administered intraperitoneally. (c) L-carnitine Group (n=7): L-carnitine (500 mg/ $\mathrm{kg}$ ) was administered intraperitoneally. (d) $\mathrm{O}_{3}+L$-carnitine Group $(\mathrm{n}=7)$ : ozone $(0.5 \mathrm{mg} / \mathrm{kg}$ of $95 \%$ oxygen plus $5 \%$ ozone gas mixture) and L-carnitine $(500 \mathrm{mg} / \mathrm{kg})$ were given intraperitoneally. (e) APAP Group (n=7): N-acetyl-paminophenol $(1 \mathrm{~g} / \mathrm{kg})$ was given orally as a single dose to induce liver damage. (f) $\mathrm{APAP}+\mathrm{O}_{3}$ Group $(\mathrm{n}=7)$ : $\mathrm{N}$-acetylp-aminophenol $(1 \mathrm{~g} / \mathrm{kg})$ was administered orally as a single dose to induce liver damage, and ozone $(0.5 \mathrm{mg} / \mathrm{kg}$ of $95 \%$ oxygen plus $5 \%$ ozone gas mixture) was applied intraperitoneally 1 hour after APAP administration. (g) APAP $+L$-carnitine Group $(\mathrm{n}=7): N$-acetyl-p-aminophenol $(1 \mathrm{~g} / \mathrm{kg})$ was administered orally as a single dose to induce liver damage, and L-carnitine (500 $\mathrm{mg} / \mathrm{kg})$ was given intraperitoneally 1 hour after APAP administration. (h) Acetaminophen $+\mathrm{O}_{3}+L$-carnitine Group $(\mathrm{n}=7)$ : $\mathrm{N}$-acetylp-aminophenol $(1 \mathrm{~g} / \mathrm{kg})$ was orally administered as a single dose to induce liver damage, and ozone $(0.5 \mathrm{mg} / \mathrm{kg}$ of $95 \%$ oxygen plus $5 \%$ ozone gas mixture) and L-carnitine (500 $\mathrm{mg} / \mathrm{kg}$ ) were given intraperitoneally 1 hour after APAP administration.

Chemicals: Acetaminophen: APAP was purchased from Atabay Pharmaceuticals and Fine Chemicals Inc. (Gebze, Turkey) and dissolved in distilled water before use. APAP was adjusted according to animal weight, was dissolved in a sufficient amount of water, and was given to the rats.

Ozone (95\% oxygen, 5\% ozone): ozone was obtained from the ozone device located at the Research and Teaching Hospital of Kafkas University Medical School.

L-carnitine: Ampoules of $5 \mathrm{ml}$, containing $1 \mathrm{~g} \mathrm{~L}$ Carnitine inner salt, $0.014 \mathrm{~mL}$ of $10 \%$ hydrochloric acid, and sterile water (L-Carnitine inner salt; Catalogue No: C0158, Sigma-Aldrich Chemie GmbH, Steinheim, Germany) were used as ready-to-use preparations.

Anesthesia and Collection of Tissue and Blood Samples: The rats were housed in a room and maintained at a temperature of $25^{\circ} \mathrm{C}$ with alternating light periods (12 hours light/12 hours dark). All animals were fed by adlibitum until the initiation of the experiments.

Before the experiment, animals were not fed overnight. Blood and tissue (liver) samples were taken immediately after performing cervical vertebra dislocation per ethical rules. Blood and tissue samples were kept at $80{ }^{\circ} \mathrm{C}$ until biochemical analyses. On the other hand, the collected liver tissues were fixed in $10 \%$ buffered formaldehyde solution. After routine procedures, $4 \mu \mathrm{m}$ thick sections of paraffin blocks were obtained and stained with Hematoxylin-Eosin (H\&E) which were evaluated under light microscopy (Olympus BX46 microscope, Olympus Inc.). The levels of ALT, AST, GGT, TAS, and MDA were determined in the blood samples, while TAS, TOS, and MDA parameters were measured in the liver tissue samples following the standard procedures. 
Statistical Analyses: Analysis of variance (ANOVA) was conducted for each variable and means of all variables for each of the experimental groups was estimated. The results were presented as mean \pm standard errors $(\mathrm{x} \pm \mathrm{SE})$. Mean separations among the groups for all variables were conducted using Tukey's multiple comparison test. All the statistical analyses were performed using the Statistical Package for the Social Sciences (SPSS, version 18.0, IBM, Armonk, New York 10504, NY, USA). Statistical significance was assessed at the $5 \%$ probability level unless otherwise indicated.

\section{RESULTS}

Histopathological evaluations: Histopathological examinations revealed that livers were normal in appearance with no change in the control group (Figure 1A) and ozone group (Figure 1B) while focal minimalmild vascular congestion was observed in L-carnitine (Figure 1C) and ozone+L-carnitine (Figure 1D) groups.

However, the liver tissues of rats exposed to APAP toxicity demonstrated to have a moderate to severe cellular damage, necrosis, hemorrhage in some areas, and vascular congestion (Figure $2 \mathrm{~A}$ ). In the $\mathrm{APAP}+\mathrm{O}_{3}$ treated group, mild, medium, and severe cellular damage were detected with varying degrees of vascular congestion in all cases, and hemorrhagic areas in two instances with focal or diffuse localization in hepatocytes (Figure 2B). No periportal inflammation and no necrosis in any of the specimens were found, while extensive cellular damage areas had started to recover from the periportal area (Figure 2B).

In the APAP+L-carnitine treated group, vascular congestion, hemorrhage, and moderate to severe cellular damage were detected in liver tissues (Figure 2C). However, no significant periportal inflammation was observed. Besides, large damage zones had started to recover from the periportal area (Figure 2C). Deviating from the $\mathrm{APAP}+\mathrm{O}_{3}$ treated group, focal periportal necrosis in a case with moderate to severe cellular damage was detected in addition to the varying degrees of hemorrhagic areas in all cases (Figure 2C).

In the $\mathrm{APAP}+\mathrm{O}_{3}+\mathrm{L}$-carnitine-treated group, vascular congestion in the liver tissues of some rats and hemorrhagic areas in two cases were discovered. When the whole liver tissue was taken into consideration, no significant periportal inflammation was observed; however, focal periportal necrosis was detected in the hepatocytes of one animal with no cellular damage and another case with moderate cellular damage (Figure 2D). It was noted that moderate cell damage areas had started to recover from the periportal region (Figure 2D). Cellular damage, vascular congestion, hemorrhage, and focal periportal necrosis were observed in the $\mathrm{APAP}+\mathrm{O}_{3}+\mathrm{L}$ carnitine group, while no periportal inflammation was detected similar to the $\mathrm{APAP}+\mathrm{O}_{3}$ treated group.

Serum and tissue oxidant and antioxidant levels: TAS, TOS, MDA levels in both serum and liver tissues and serum ALT, AST and GGT levels significantly differed among groups $(\mathrm{p} \leq 0.05)$.

Acetaminophen administration caused an increase in the levels of TOS both in the serum and in the liver tissue (Table 1).

The differences in the serum TOS levels among groups other than APAP were not significant $(p>0.05)$ whereas the liver tissue TOS levels among other groups were further structured. The serum TOS levels of Lcarnitine Control, $\mathrm{O}_{3}+\mathrm{L}$-carnitine and $\mathrm{APAP}+\mathrm{O}_{3}$ groups ranked lowest. Control, $\mathrm{O}_{3}$-Control, and $\mathrm{APAP}+\mathrm{O}_{3}+\mathrm{L}-$ carnitine groups ranked an intermediate pattern where they were not significantly different from highest or lowest groups. An inverse pattern was observed in TAS levels as expected. Serum and liver tissue TAS level of APAP group was lowest among all the groups. Tissue TAS level was highest in L-carnitine Control group followed by Control and $\mathrm{O}_{3} \mathrm{~L}$-carnitine. A third group consisted of $\mathrm{O}_{3}$-Control and $\mathrm{APAP}+\mathrm{O}_{3}+\mathrm{L}$-carnitine groups. $\mathrm{APAP}+\mathrm{O}_{3}$ and APAP + L-carnitine groups were significantly lower than all the groups except the lowest APAP group. In serum TAS levels, $\mathrm{O}_{3}$-Control, L-carnitine Control, $\mathrm{APAP}+\mathrm{O}_{3}$, $\mathrm{APAP}+\mathrm{L}$-carnitine and $\mathrm{APAP}+\mathrm{O}_{3}+\mathrm{L}$-carnitine groups had highest TAS levels whereas APAP had the lowest. Both Control, $\mathrm{O}_{3}+\mathrm{L}$-carnitine groups demonstrated an intermediate pattern that is not different from highest or lowest groups (Table 1).

The level of MDA in serum and liver tissue and serum ALT and AST levels followed a rather simpler pattern where APAP group had the higher levels and all other groups collectively composed the lower group (Table 2). It was noted that APAP group had the highest mean GGT level ( $\mathrm{p} \leq 0.05)$, and Control, L-carnitine, $\mathrm{O}_{3}+\mathrm{L}$ carnitine, $\mathrm{APAP}+\mathrm{L}$-carnitine, $\quad \mathrm{APAP}+\mathrm{O}_{3}+\mathrm{L}$-carnitine groups had a lower level. $\mathrm{APAP}+\mathrm{O}_{3}$ administration and $\mathrm{O}_{3}$-Control GGT levels were in the level that is not statistically different from either APAP group or the other lower groups (Table 2). 


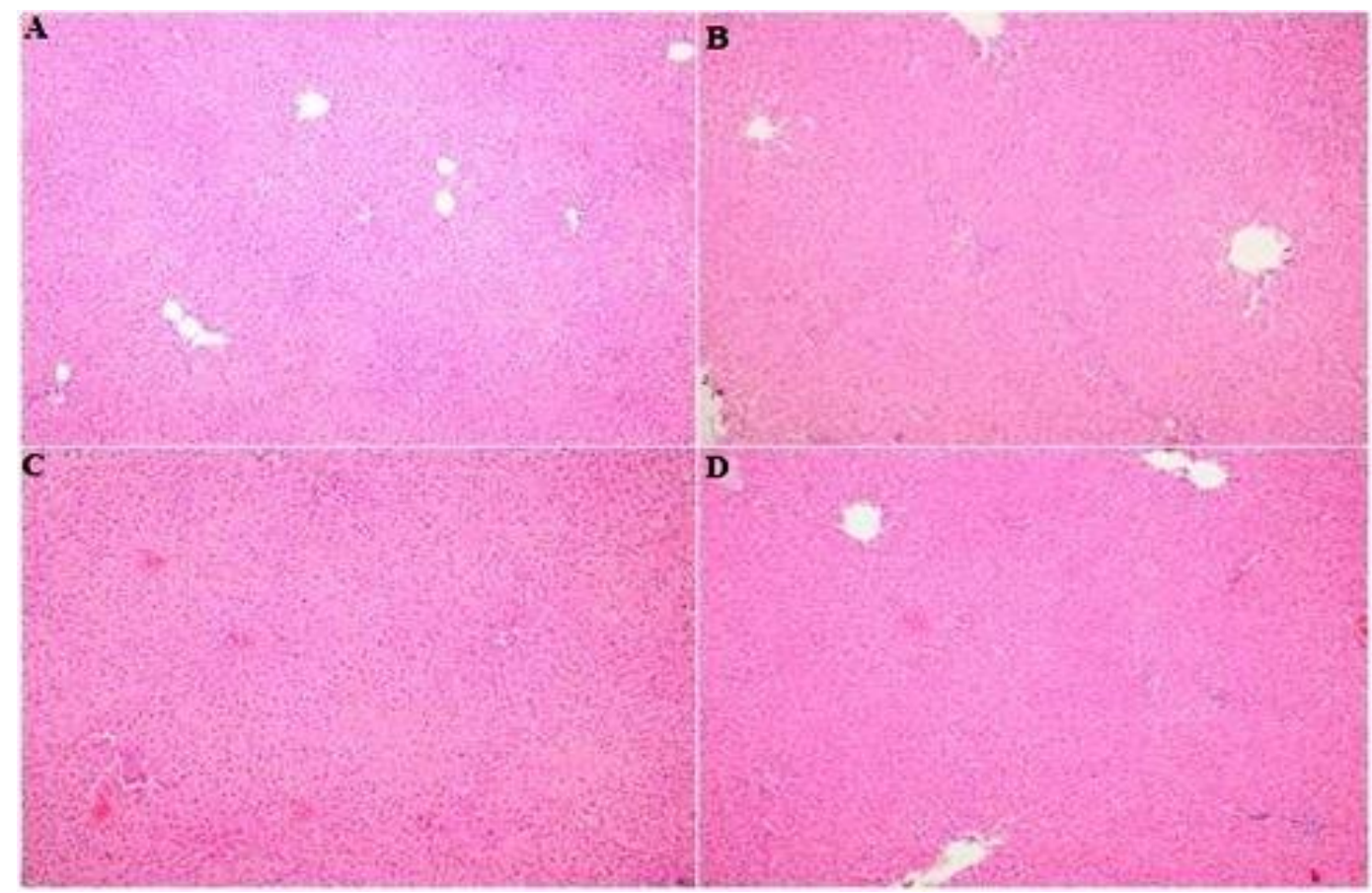

Figure 1: A: Control group with normal histology $(\mathrm{H} \& \mathrm{E}, 100 x)$, B: Ozone group with normal histology $(\mathrm{H} \& \mathrm{E}$, $100 x), C$ : Mild vascular congestion in L-carnitine group $(H \& E, 100 x)$, D: Minimal vascular congestion in ozone+ L-carnitine group (H\&E, 100x).

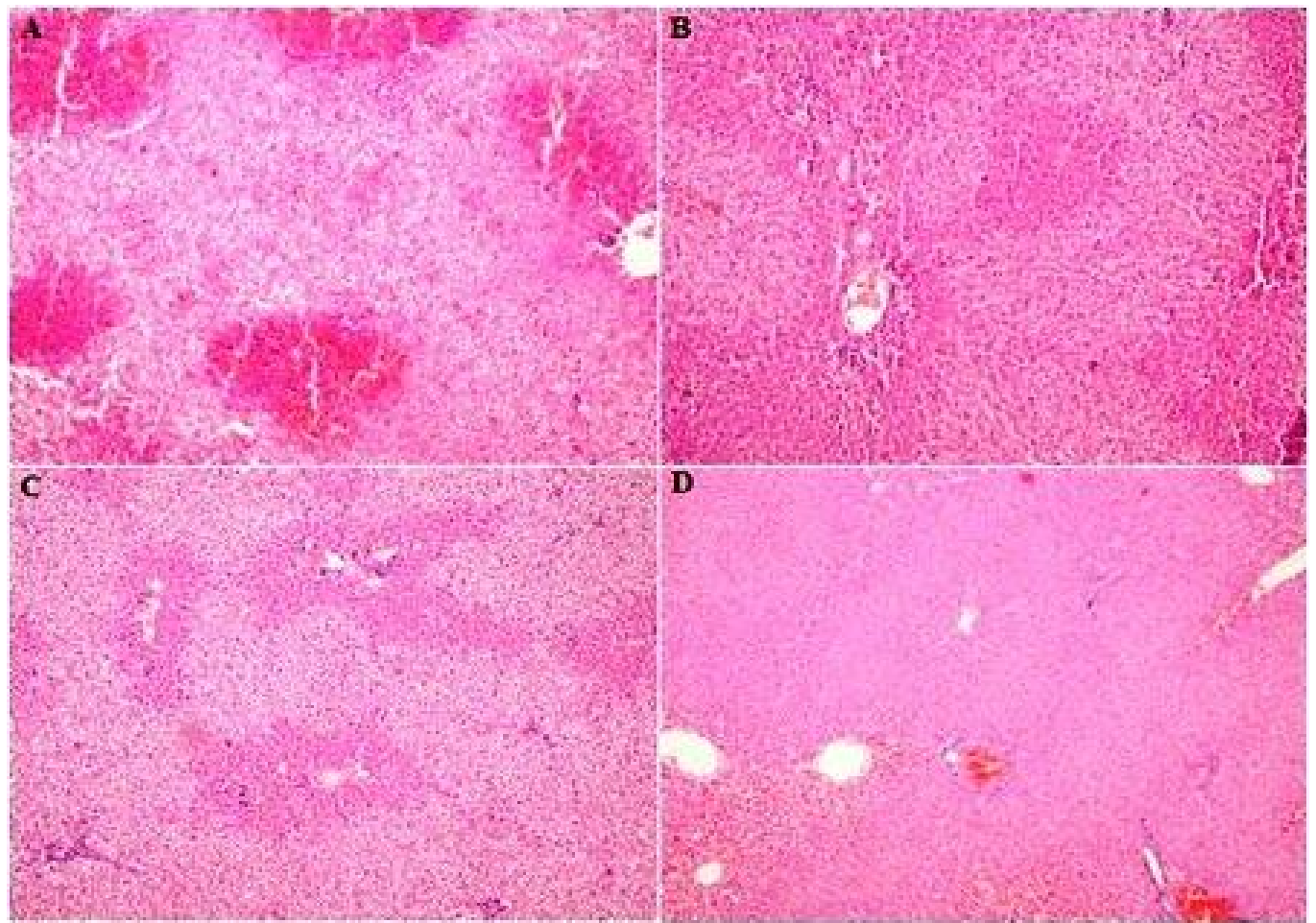

Figure 2: A: APAP group with moderate-severe cellular damage, necrosis and (H\&E, 200x), B: APAP+ ozone group with varying degrees of cellular damage and recovery from periportal areas (H\&E, 200x), C: APAP+ L-carnitine group with varying degrees of cellular damage and recovery from periportal areas (H\&E, 200x), D: APAP+ ozone+ L-carnitine group with vascular congestion in and hemorrhagic areas (H\&E, 200x). 
Table 1. Serum and tissue TAS and TOS levels (mean \pm SE) of 8 groups in the present study.

\begin{tabular}{lcccc}
\hline \multicolumn{1}{c}{ Groups } & $\begin{array}{c}\text { Tissue TAS } \\
\text { Mean } \pm \text { SE }\end{array}$ & $\begin{array}{c}\text { Serum TAS } \\
\text { Mean } \pm \text { SE }\end{array}$ & $\begin{array}{c}\text { Tissue TOS } \\
\text { Mean } \pm \text { SE }\end{array}$ & $\begin{array}{c}\text { Serum TOS } \\
\text { Mean } \pm \text { SE }\end{array}$ \\
\hline Control & $3.88 \pm 0.10_{\mathrm{ab}}$ & $2.04 \pm 0.15_{\mathrm{ab}}$ & $9.60 \pm 0.41_{\mathrm{b}}$ & $2.84 \pm 0.15_{\mathrm{bc}}$ \\
$\mathrm{O}_{3}$ Control & $3.33 \pm 0.21_{\mathrm{bc}}$ & $2.08 \pm 0.17_{\mathrm{a}}$ & $10.92 \pm 0.34_{\mathrm{b}}$ & $3.14 \pm 0.30_{\mathrm{bc}}$ \\
$\mathrm{L}_{\text {-carnitine Control }}$ & $4.16 \pm 0.07_{\mathrm{a}}$ & $2.39 \pm 0.16_{\mathrm{a}}$ & $10.30 \pm 0.57_{\mathrm{b}}$ & $2.41 \pm 0.29_{\mathrm{c}}$ \\
$\mathrm{O}_{3} \mathrm{~L}-$-carnitine & $3.95 \pm 0.14_{\mathrm{ab}}$ & $2.00 \pm 0.09_{\mathrm{ab}}$ & $10.00 \pm 0.94_{\mathrm{b}}$ & $2.01 \pm 0.38_{\mathrm{c}}$ \\
$\mathrm{APAP}$ & $2.38 \pm 0.17_{\mathrm{d}}$ & $1.40 \pm 0.15_{\mathrm{b}}$ & $15.25 \pm 1.01_{\mathrm{a}}$ & $6.39 \pm 0.34_{\mathrm{a}}$ \\
$\mathrm{APAP}+\mathrm{O}_{3}$ & $3.11 \pm 0.18_{\mathrm{c}}$ & $2.35 \pm 0.06_{\mathrm{a}}$ & $11.20 \pm 0.34_{\mathrm{b}}$ & $2.49 \pm 0.41_{\mathrm{c}}$ \\
$\mathrm{APAP}+\mathrm{L}-$-carnitine & $3.16 \pm 0.19_{\mathrm{c}}$ & $2.42 \pm 0.22_{\mathrm{a}}$ & $11.17 \pm 1.55_{\mathrm{b}}$ & $4.42 \pm 0.89_{\mathrm{b}}$ \\
$\mathrm{APAP}+\mathrm{O}_{3}+\mathrm{L}-\mathrm{carnitine}$ & $3.34 \pm 0.11_{\mathrm{bc}}$ & $2.58 \pm 0.06_{\mathrm{a}}$ & $11.33 \pm 0.65_{\mathrm{b}}$ & $2.90 \pm 0.54_{\mathrm{bc}}$ \\
\hline
\end{tabular}

${ }^{*}$ Values within columns followed by different letters are significantly different at $\mathrm{P} \leq 0.05$.

Table 2. Serum and tissue MDA levels and serum ALT, AST, and GGT levels (mean \pm SE) of 8 groups in the present study.

\begin{tabular}{lccccc}
\hline \multicolumn{1}{c}{ Groups } & $\begin{array}{c}\text { Tissue MDA } \\
\text { Mean } \pm \text { SE }\end{array}$ & $\begin{array}{c}\text { Serum MDA } \\
\text { Mean } \pm \text { SE }\end{array}$ & $\begin{array}{c}\text { Serum ALT } \\
\text { Mean } \pm \text { SE }\end{array}$ & $\begin{array}{c}\text { Serum AST } \\
\text { Mean } \pm \text { SE }\end{array}$ & $\begin{array}{c}\text { Serum GGT } \\
\text { Mean } \pm \text { SE }\end{array}$ \\
\hline Control & $0.21 \pm 0.01_{\mathrm{b}}$ & $0.05 \pm 0.004_{\mathrm{b}}$ & $65.30 \pm 2.49_{\mathrm{b}}$ & $226.80 \pm 12.17_{\mathrm{b}}$ & $1.20 \pm 0.25_{\mathrm{b}}$ \\
$\mathrm{O}_{3}$ Control & $0.23 \pm 0.02_{\mathrm{b}}$ & $0.05 \pm 0.002_{\mathrm{b}}$ & $73.06 \pm 4.24_{\mathrm{b}}$ & $204.74 \pm 9.91_{\mathrm{b}}$ & $1.34 \pm 0.26_{\mathrm{ab}}$ \\
$\mathrm{L}_{\text {-carnitine Control }}$ & $0.28 \pm 0.01_{\mathrm{b}}$ & $0.05 \pm 0.002_{\mathrm{b}}$ & $68.06 \pm 1.64_{\mathrm{b}}$ & $205.34 \pm 3.28_{\mathrm{b}}$ & $0.76 \pm 0.10_{\mathrm{b}}$ \\
$\mathrm{O}_{3}+\mathrm{L}-$-carnitine & $0.22 \pm 0.02_{\mathrm{b}}$ & $0.04 \pm 0.004_{\mathrm{b}}$ & $83.66 \pm 5.43_{\mathrm{b}}$ & $272.22 \pm 6.92_{\mathrm{b}}$ & $0.68 \pm 0.10_{\mathrm{b}}$ \\
$\mathrm{APAP}$ & $0.71 \pm 0.06_{\mathrm{a}}$ & $0.08 \pm 0.005_{\mathrm{a}}$ & $584.28 \pm 166.8_{\mathrm{a}}$ & $528.43 \pm 104.2_{\mathrm{a}}$ & $2.18 \pm 0.20_{\mathrm{a}}$ \\
$\mathrm{APAP}+\mathrm{O}_{3}$ & $0.49 \pm 0.09_{\mathrm{b}}$ & $0.05 \pm 0.007_{\mathrm{b}}$ & $175.78 \pm 15.21_{\mathrm{b}}$ & $219.64 \pm 47.34_{\mathrm{b}}$ & $1.36 \pm 0.14_{\mathrm{ab}}$ \\
$\mathrm{APAP}+\mathrm{L}-$ carnitine & $0.12 \pm 0.01_{\mathrm{b}}$ & $0.06 \pm 0.002_{\mathrm{b}}$ & $127.37 \pm 4.92_{\mathrm{b}}$ & $223.87 \pm 45.35_{\mathrm{b}}$ & $1.13 \pm 0.08_{\mathrm{b}}$ \\
$\mathrm{APAP}+\mathrm{O}_{3}+\mathrm{L}-$ carnitine & $0.17 \pm 0.01_{\mathrm{b}}$ & $0.05 \pm 0.005_{\mathrm{b}}$ & $141.67 \pm 15.27_{\mathrm{b}}$ & $269.53 \pm 36.29_{\mathrm{b}}$ & $1.21 \pm 0.35_{\mathrm{b}}$ \\
\hline
\end{tabular}

${ }^{*}$ Values within columns followed by different letters are significantly different at $\mathrm{P} \leq 0.05$.

\section{DISCUSSION}

In our study, a dose $1 \mathrm{~g} / \mathrm{kg}$ of APAP was administered by oral gavage. We initially deduced the effect of APAP on liver using microscopic evaluations. The microscopic imaging indicated the moderate to severe cellular damage, necrosis, hemorrhage in some areas, and vascular congestion in liver tissues of rats exposed to APAP toxicity. The absence of cellular damage, necrosis and hemorrhage in other groups were a clear indication of the effect of APAP damage in liver tissue. The microscopic results were consistent with the earlier reports documenting APAP damage in various animals (Doyon and Klein-Schwartz, 2009; Bhattacharyya et al., 2013). When microscopic evaluation results were compared among groups, we found that ozone and L-carnitine alone and combined $\left(\mathrm{O}_{3}+\mathrm{L}\right.$-carnitine treatments $)$ were effective in reducing APAP-induced hepatotoxicity. Thus, we concluded that they increased detoxification capacity by elevating the levels of GSH in erythrocytes and protected the liver against the damages of oxidants by activating the antioxidant defense mechanism.

We also compared microscopic imaging with the oxidant/antioxidant levels and detected that the evaluations were consistent with the oxidant/antioxidant levels and liver tissue/serum enzyme measurements. The serum AST, ALT, and GGT levels were significantly increased in the APAP-induced toxicity group compared to the control group. Increased values were indicative of liver damage. In the ozone-administered group, serum AST and ALT levels were significantly different compared to the APAP toxicity group, while GGT levels were significantly lower. In the $\mathrm{APAP}+\mathrm{O}_{3}+\mathrm{L}$-carnitine group, AST and GGT levels were significantly decreased compared to the APAP-toxicity group. The low levels of serum AST, ALT, and GGT in the APAP+O $3, \mathrm{APAP}+\mathrm{L}-$ carnitine, and $\mathrm{APAP}+\mathrm{O}_{3}+\mathrm{L}$-carnitine groups compared to the toxicity group, as well as, the absence of a significant difference compared to the control group, indicated that tissue damage was minimized. A same dose of APAP was administered in an earlier study along with the ozone to examine its possible therapeutic effects. The study reported a significant increase in the levels of serum AST and ALT in the APAP-toxicity group compared to the control and treatments groups, while the levels of serum AST and ALT were decreased in the ozone-treated group (Gul et al., 2012). In studies involving APAP-induced hepatotoxicity, necrosis, sinusoidal dilatation, increases in the activation of Kupffer cells (star-shaped) and cell hypertrophy has been observed in the liver (Ito et al., 2003; McCuskey, 2006). Tezcan et al., (2018) also reported that ozone administration reduces necrosis statistically significantly in APAP-induced hepatotoxicity in mice 
(Tezcan et al., 2018). Parallel with the literature, we observed that ozone, L-carnitine, and ozone $+\mathrm{L}-$ carnitine caused a recovery in the histopathological liver damage findings and regeneration in the liver damage induced by APAP.

One of the main focus of the present study was to infer the combined effect of L-carnitine and ozone on the APAP induced hepatotoxicities. Therefore, we compared effect of L-carnitine, and ozone separately and their combined effect to the APAP induced group. We observed that compare to $\mathrm{APAP}+\mathrm{O}_{3}$ and $\mathrm{APAP}+\mathrm{L}$-carnitine groups, $\mathrm{APAP}+\mathrm{O}_{3}+\mathrm{L}$-carnitine group had a progressively higher value for tissue and serum TAS levels. In fact, the highest serum TAS value among all eight groups was observed in $\mathrm{APAP}+\mathrm{O}_{3}+\mathrm{L}$-carnitine group, albeit not significant. An analogous but inverse pattern was evident in serum MDA levels where $\mathrm{APAP}+\mathrm{O}_{3}+\mathrm{L}$-carnitine group had lowest value and grouped with $\mathrm{APAP}+\mathrm{O}_{3}$ and $\mathrm{APAP}+\mathrm{L}$-carnitine groups. It was reported earlier that MDA, an important tissue damage marker, has increased as a result of lipid peroxidation. Gul et al., (2012) reported that APAPinduced hepatotoxicity led to an increase in the levels of MDA activity. However, ozone administration decreased the level of MDA activity compared to the toxicity group (Gul et al., 2012). The MDA activity was reported to be significantly increased in the APAP toxicity group and decreased in the L-carnitine treated group compared to the APAP group (Cetinkaya et al., 2009). The study also reported that MDA, the final product of lipid peroxidation, caused damage to both the surrounding and distant tissues. The decrease in MDA levels after treatment and the recovery of hepatotoxicity were found to be related to the prevention of lipid peroxidation and reduction of the effects of oxidative stress by administering L-carnitine (Cetinkaya et al., 2009). We also observed a similar pattern in ozone treated groups. However, we did not detect a clear pattern of where $\mathrm{APAP}+\mathrm{O}_{3}+\mathrm{L}$-carnitine group being superior to either $\mathrm{APAP}+\mathrm{O}_{3}$ and $\mathrm{APAP}+\mathrm{L}-$ carnitine groups in terms of liver hepatoxicity parameters estimated in the current study. Absence of such a pattern could be attributed to the sample size tested here. As we observed a superior pattern in terms of numbers and significance in some of the parameters a larger sample size may be more powerful to detect a statistically significant signal. Such a test would be invaluable to discern a more powerful therapy method that combines ozone and Lcarnitine.

In conclusion, in APAP-induced hepatotoxicity, ozone, L-carnitine and ozone $+\mathrm{L}$-carnitine treatments decreased the necrotic and hemorrhagic areas, prevented the periportal inflammation and created regeneration in the liver tissue. Thus, we believe that ozone treatment was effective due to having the capability of increasing the detoxification capacity of cells by increasing GSH levels in the hepatocytes. We also think that ozone, L-carnitine, and ozone + L-carnitine have antioxidant properties, and they protect the organism and inhibit oxidative stress by activating the antioxidant mechanism.

Acknowledgements: This study was supported by Kafkas University Scientific Research Projects Coordination Unit (Project No: 2016-TS-86).

\section{REFERENCES}

Abiko, Y., I. Ishii, S. Kamata, Y. Tsuchiya, Y. Watanabe, H. Ihara, T. Akaike and Y. Kumagai (2015). Formation of sulfur adducts of N-acetyl-pbenzoquinoneimine, an electrophilic metabolite of acetaminophen in vivo: participation of reactive persulfides. Chem. Res. Toxicology. 28(9): 1796-1802.

Bernal, W., G. Auzinger, A. Dhawa and J. Wendon (2010). Acute liver failure. The Lancet. 376 (9736): 190201.

Bhattacharyya, S., L. Pence, R. Beger, S. Chaudhuri, S. McCullough, K. Yan, P. Simpson, L. Hennings, J. Hinson and L. James (2013). Acylcarnitine profiles in acetaminophen toxicity in the mouse: comparison to toxicity, metabolism and hepatocyte regeneration. Metabolites. 3(3): 606622.

Bocci, V., I. Zanardi and V. Travagli (2011). Has oxygenozonetherapy a future in medicine. J Exp Integr Med. 1: 5-11.

Cetinkaya, A., B. Kantarçeken, E. Bülbüloğlu and E. B. Kurutas (2009). The effects of L-carnitine on cyclophosphamide-induced oxidative liver and intestinal damage in rats. Türkiye Klinikleri Tip Bilimleri Dergisi. 29(5): 1161-1167.

Demirbag, S., B. Uysal, A. Guven, T. Cayci, M. Ozler, A. Ozcan, U. Kaldirim, I. Surer and A. Korkmaz (2010). Effects of medical ozone therapy on acetaminophen-induced nephrotoxicity in rats. Renal Failure. 32(4): 493-497.

Demiroren, K., Y. Dogan, H. Kocamaz, I. H. Ozercan, S. Ilhan, B. Ustundag and I. H. Bahcecioglu (2014). Protective effects of L-carnitine, Nacetylcysteine and genistein in an experimental model of liver fibrosis. Clin. and Res. in Hepatology and Gastroenterology. 38(1): 63-72.

Doyon, S. and W. Klein-Schwartz (2009). Hepatotoxicity despite early administration of intravenous $\mathrm{N}$ acetylcysteine for acute acetaminophen overdose. Academic Emergency Medicine, 16(1): 34-39.

Ghirardi, O., S. Milano, M. T. Ramacci and L. Angelucci (1989). Long-term acetyl-L-carnitine preserves spatial learning in the senescent rat. Progress in Neuro-Psychopharmacol. \& Biol. Psychiatry.

Gul, H., B. Uysal, E. Cakir, H. Yaman, E. Macit, A. O. Yildirim, Y. E. Eyi, U. Kaldirim, E. Oztas, E. O. Akgul, T. Cayci, M. Ozler, T. Topal, S. Oter, A. 
Korkmaz, M. Toygar and S. Demirbag (2012). The protective effects of ozone therapy in a rat model of acetaminophen-induced liver injury. Environmental Toxicology and Pharmacol. 34(1): 81-86.

Ito, Y., N. W. Bethea, E. R. Abril and R. S. Mccuskey (2003). Early hepatic microvascular injury in response to acetaminophen toxicity. Microcirculation. 10(5): 391-400.

James, L. P., P. R. Mayeux and J. A. Hinson (2003). Acetaminophen-induced hepatotoxicity. Drug Metabolism and Disposition. 31(12): 1499-1506.

Lee, W. M. (2017). Acetaminophen (APAP) hepatotoxicity-isn't it time for APAP to go away? J. Hepatology. 67(6): 1324-1331.

Li, L.-J., Y.-G. Yang, Z.-L. Zhang, S.-F. Nie, Z. Li, F. Li, H.-Y. Hua, Y.-J. Hu, H.-S. Zhang and Y.-B. Guo (2007). Protective effects of medical ozone combined with traditional Chinese medicine against chemically-induced hepatic injury in dogs. World J. Gastroenterology: WJG. 13(45): 5989.

McCuskey, R. S. (2006). Sinusoidal endothelial cells as an early target for hepatic toxicants. Clin. Hemorheology and Microcirculation. 34(1, 2): 510 .
Ostapowicz, G., R. J. Fontana, F. V. Schioødt, A. Larson, T. J. Davern, S. H. Han, T. M. McCashland, A. O. Shakil, J. E. Hay, L. Hynan, J. S. Crippin, A. T. Blei, G. Samuel, J. Reisch, W. M. Lee and U.S. Acute Liver Failure Study Group (2002). Results of a prospective study of acute liver failure at 17 tertiary care centers in the United States. Annals of Internal Medicine. 137(12): 947-954.

Ranganathan, S. S., M. G. Sathiadas, S. Sumanasena, M. Fernandopulle, S. P. Lamabadusuriya and B. M. R. Fernandopulle (2006). Fulminant hepatic failure and paracetamol overuse with therapeutic intent in febrile children. The Indian J. of Pediatrics. 73(10): 871-875.

Saleh, S., M. El-Ridi, S. Zalat, S. El-Kotb and S. Donia (2014). Additive effect of ozone therapy to insulin in the treatment of diabetic rats. Menoufia Medical J. 27(1): 85.

Sobczyńska-Rak, A., B. Żylińska, I. Polkowska, P. Silmanowicz and T. Szponder (2019). Use of ozone in medicine and veterinary practice. Medycyna Weterynaryjna. 75(1): 24-29.

Tezcan, A. H., O. Ozturk, S. Ustebay, Y. Adali and H. Yagmurdur (2018). The beneficial effects of ozone therapy in acetaminophen-induced hepatotoxicity in mice. Pharmacological Rep. 70(2): 340-345. 